\title{
Lost information? The fate of papers presented at the 40th Society for Social Medicine Conference
}

\author{
Mark Petticrew, Simon Gilbody, Fujian Song
}

It has been known since the 1950s that half of papers presented at conferences are never published. ${ }^{12}$ If the decision to publish or to delay publishing is related to study outcome, systematic reviews of such studies may be subject to publication bias. ${ }^{34}$ One meta-analysis has reported a two year publication rate of $51 \%$, but found weak evidence that projects with significant results were more likely to be published. ${ }^{3}$ A recent study found stronger evidence of such an effect, but the phenomenon has been little studied. ${ }^{5}$

This study examined the fate of studies presented orally at the Society for Social Medicine 40th annual conference in 1996. The rate of full publication within two years, and the association between study outcome and publication status were investigated.

\section{Methods \\ Abstracts of all 77 orally presented studies were reviewed. Full publications relating to each abstract were sought in electronic databases. Where a full publication was not found, or where it was unclear whether a publication related to a particular abstract, the authors were contacted for clarification. Abstracts were then assessed by two independent reviewers, blinded to publication status, and to the authors' names and affiliations. Next, the study results were categorised as positive, negative, or uncertain, based on a subjective assessment of the study results and the authors' conclusions. Disagreements were then resolved by blinded review of the relevant abstracts by a third reviewer.}

\section{Results}

Four abstracts $(5 \%)$ described trials or reviews of trials; $61(79 \%)$ described observational studies (including surveys, and epidemiological studies), and $12(16 \%)$ were qualitative or discussion papers. The fate of 74 of the 77 abstracts could be determined (96\%).

PUBLICATION RATE

At two years, half the studies $(50.6 \%)$ had been published, and six ( $8 \%)$ were "in press" (table $1)$. A quarter $(26 \%)$ were still undergoing revi9 March 1999

Table 1 Publication status of abstracts

\begin{tabular}{lccc}
\hline Publication status & Frequency & Per cent & $\begin{array}{l}\text { Number (\%) with } \\
\text { negative/uncertain findings }\end{array}$ \\
\hline Published & 39 & 50.6 & $21 / 39(54)$ \\
In press & 6 & 7.8 & $2 / 6(33)$ \\
In revision & 20 & 26.0 & $8 / 20(40)$ \\
Do not intend to publish & 8 & 10.4 & $6 / 8(75)$ \\
Ongoing study & 1 & 1.3 & $1 / 1(100)$ \\
Not traced & 3 & 3.9 & $3 / 3(100)$ \\
Total & 77 & 100.0 & \\
\hline
\end{tabular}

${ }^{\star}$ Either in response to referee comments, or before submission. sions. A small proportion of authors (10.4\%) reported that they did not intend to publish the paper. None cited study outcome as a reason.

PUBLICATION STATUS BY FINAL DECISION

There was $79.2 \%$ agreement between the two main reviewers on the coding of study outcome. As there were few "negative" studies, the uncertain and negative categories were grouped. There was no association between study outcome and full publication, though numbers for analysis are small (relative risk $=0.97 ; 95 \%$ CI: 0.60, 1.57). However, those with negative or uncertain results were less likely to have at least started the process of publication (that is, were published, or in press, or in revision) ( $\mathrm{RR}=0.80 ; 95 \% \mathrm{CI}: 0.66,0.97)$. (Some of those stated to be "in revision" may also of course never be fully published).

\section{Discussion}

These results confirm that half of studies remain unpublished after conferences. They also suggest that this " $50 \%$ rule" is not confined to controlled trials. There was evidence that negative or uncertain findings are associated with non-publication, though the numbers were too small to analyse the association between publication status and solely negative results in detail. However, of the seven studies with negative results, four had been published and three had not. Reasons given by the authors for non-publication included "unreasonable" changes required by journal editors; lack of time; and disagreement with other authors over revisions.

It is also possible that the qualitative papers and discussion papers, which tended to be categorised as having "uncertain" findings, may never have been intended to be published. Grouping these with "negative" studies could then be misleading. Any future analysis could examine publication rates of abstracts with clearly negative findings over a number of years, which may give large enough numbers to investigate these negative studies in more detail.

Early studies in this area reported that publication "saturates" around $50 \%$ at 5 years. ${ }^{2}$ A 1994 meta-analysis of 11 studies of abstracts also found publication rates at two years ranging from approximately $30 \%$ to $50 \%$, with a combined full publication rate of $51 \%$. $^{3}$ Papers presented at conference that never achieved full publication were referred to in a 1959 paper as "lost information." If it is indeed the case that half of papers presented at conferences are not published in full, then this emphasises the importance of publishing conference 
proceedings, and underlines again the need for systematic reviewers to search these proceedings when carrying out reviews, to avoid introducing bias. ${ }^{6}$

The number of orally presented abstracts for analysis in this study was small, representing only one year's data, but the results on publication rates are consistent with previous research on controlled trials cited above. A further source of bias lies in the selection of abstracts for presentation. ${ }^{5}$ Further research could examine the effect of this, and of other characteristics of abstracts on publication rates at longer periods of follow up.

We wish to thank the authors who contributed additional information about their abstracts.
Funding: none.

Conflicts of interest: none.

1 Liebesny F. Lost information: unpublished conference papers. Proceedings of the International Conference on Scientific Information 1959;2:475-9.

2 Oseman RH. Conferences and their literature. London: Library Association Publishing, 1989.

3 Scherer RW, Dickersin K, Langenberg P. Full publication of results initially presented in abstracts. A meta-analysis. fAMA 1994;272:158-62.

4 Egger M, Davey Smith G. Bias in location and selection of studies. BMf 1998; 316:61-6.

5 Callaham ML, Wears RL, Weber EJ, et al. Positive-outcome bias and other limitations in the outcome of research abstracts submitted to a scientific meeting. $f A M A$ 1998;280:254-7.

6 Clarke M. Comment on: Half of medical research described in published abstracts is not published in full after two years. Cochrane Methods Working Group Newsletter, June 1998. 